Cossacks in Jamaica, Ukraine at the Antipodes Essays in Honor of Marko Pavlyshyn 


\section{Ukrainian Studies}

Series Editor

Vitaly Chernetsky (University of Kansas) 


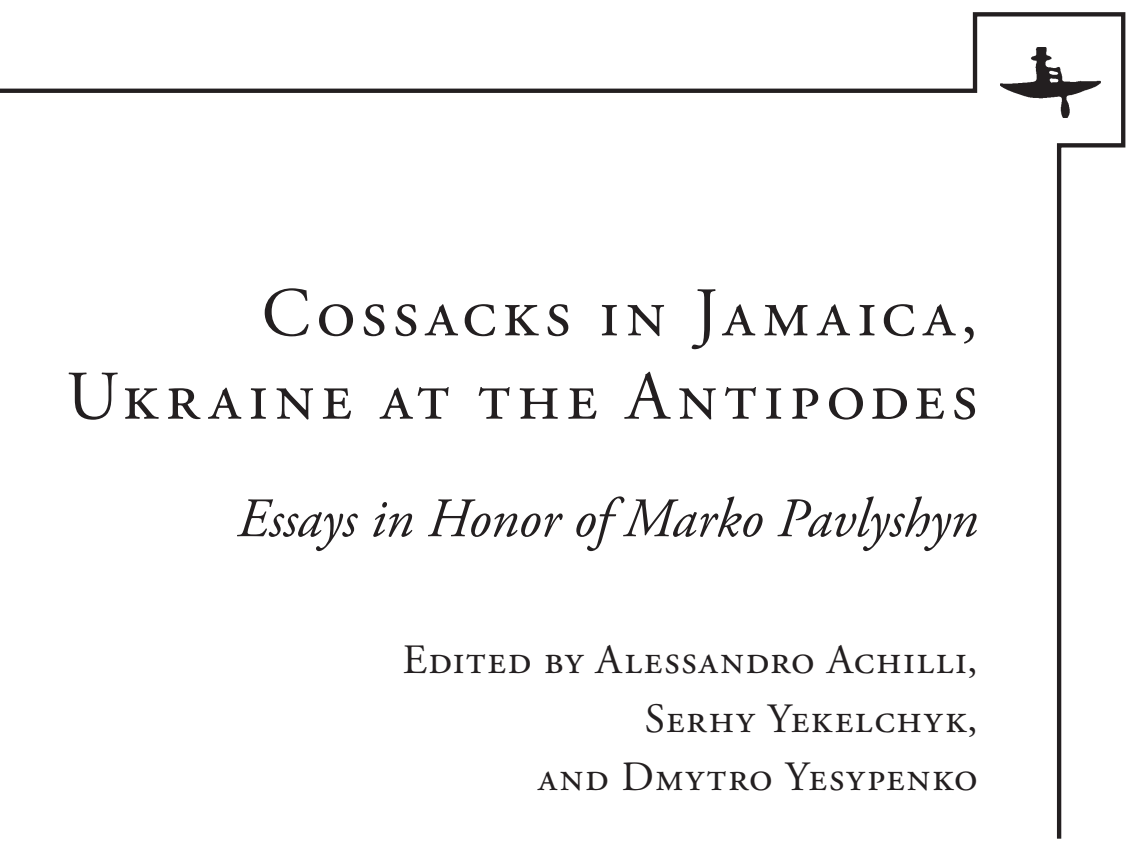

BOSTON 
Library of Congress Cataloging-in-Publication Data

Names: Pavlyshyn, Marko, honoree. I Achilli, Alessandro, editor. I

Yekelchyk, Serhy, editor. I Yesypenko, Dmytro, editor.

Title: Cossacks in Jamaica, Ukraine at the Antipodes : essays in honor of Marko Pavlyshyn / edited by Alessandro Achilli, Serhy Yekelchyk, and Dmytro Yesypenko.

Description: Boston : Academic Studies Press, 2020. I Series: Ukrainian studies series I Includes bibliographical references. I In English and Ukrainian.

Identifiers: LCCN 2019058078 (print) | LCCN 2019058079 (ebook) | ISBN 9781644693018 (hardback) I ISBN 9781644693025 (adobe pdf)

Subjects: LCSH: Ukrainian literature--History and criticism. I Ukraine--Foreign relations--1991- | Ukraine--Civilization.

Classification: LCC PG3905 .C67 2020 (print) I LCC PG3905 (ebook) I DDC 891.7/909--dc23

LC record available at https://lccn.loc.gov/2019058078

LC ebook record available at https://ccn.loc.gov/2019058079

Copyright (C) 2020 Academic Studies Press. All rights reserved.

ISBN 9781644693018 (hardcover)

ISBN 9781644693025 (ebook, PDF)

ISBN 9781644693766 (ePub)

Book design by Tatiana Vernikov.

Cover design by Ivan Grave.

On the cover: Stepan Chwyla, The Last Aborigine (1987, from the collection

of the Kyiv Museum of Ukrainian Diaspora; reproduced by permission).

Published by Academic Studies Press

1577 Beacon Street

Brookline, MA 02446, USA

press@academicstudiespress.com

www.academicstdiespress.com 